\title{
Peptide aptamers as new tools to modulate clathrin-mediated internalisation - inhibition of MT1-MMP internalisation
}

\author{
Rochana D Wickramasinghe ${ }^{1}$, Paul Ko Ferrigno ${ }^{1,3}$, Christian Roghi ${ }^{*}$
}

\begin{abstract}
Background: Peptide aptamers are combinatorial protein reagents that bind to targets with a high specificity and a strong affinity thus providing a molecular tool kit for modulating the function of their targets in vivo.

Results: Here we report the isolation of a peptide aptamer named swiggle that interacts with the very short (21 amino acid long) intracellular domain of membrane type 1-metalloproteinase (MT1-MMP), a key cell surface protease involved in numerous and crucial physiological and pathological cellular events. Expression of swiggle in mammalian cells was found to increase the cell surface expression of MT1-MMP by impairing its internalisation. Swiggle interacts with the LLY573 internalisation motif of MT1-MMP intracellular domain, thus disrupting the interaction with the $\mu 2$ subunit of the AP-2 internalisation complex required for endocytosis of the protease. Interestingly, swiggle-mediated inhibition of MT1-MMP clathrin-mediated internalisation was also found to promote MT1-MMP-mediated cell migration.
\end{abstract}

Conclusions: Taken together, our results provide further evidence that peptide aptamers can be used to dissect molecular events mediated by individual protein domains, in contrast to the pleiotropic effects of RNA interference techniques.

\section{Background}

Peptide aptamers (PAs) are small, artificially engineered proteins conceptually similar to antibodies [1]. PAs consist of a stable, ideally inert scaffold protein with an inserted constrained peptide moiety. This in effect presents a small peptide surface within the tertiary structure of the scaffold which serves as the binding site for a target protein. In contrast to most of the more than 40 non-antibody scaffolds described to date [2], PAs are usually isolated by yeast-two hybrid screening of large libraries of PAs that contain random peptide inserts against a bait protein of interest. Selection of PAs in eukaryotic cells in vivo may allow the identification of interactors that are more easily transferable to mammalian cells than interactors identified using in vitro techniques such as phage-display. PA technology is well established, with PAs showing biological activity against a wide variety of proteins from different organisms,

\footnotetext{
* Correspondence: chr26@cam.ac.uk

2University of Cambridge, Department of Oncology, Cambridge Research Centre, Li Ka Shing Centre, Robinson Way, Cambridge, CB2 ORE, UK
}

including the human and $D$. melanogaster Cdk2 proteins [1,3], the E. coli thymidylate synthase (ThyA) protein [4], the E6 and E7 proteins from human papilloma virus (HPV) [5,6], the human EGF receptor [7], and the transcription factors Stat3 [8] and the BCL-6 [9]. Importantly, some PAs have also been found to block functions of their target proteins in vivo, such as human Cdk2 [10], D. melanogaster Cdk1 and 2 [3], E2F [11], p53 [12], Stat3 [8], Nr-13 [13], and BCL-6 [9].

Membrane-type 1 Matrix Metalloproteinase (MT1MMP, also known as MMP-14), is a member of the large MMP family of enzymes. MT1-MMP plays a major role in the dynamic remodelling of the extra-cellular matrix (ECM) and has been reported to directly degrade a broad spectrum of ECM proteins, including collagen types I, II, and III, fibronectin, laminin 1, laminin 5, fibrin, and aggrecan $[14,15]$. MT1-MMP has also been reported to activate proMMP-2 and proMMP-13 $[16,17]$, thereby indirectly increasing its proteolytic repertoire on or near the cell surface. The protease also plays a role in the processing of a growing number of

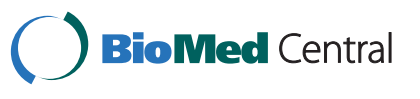

(c) 2010 Wickramasinghe et al; licensee BioMed Central Ltd. This is an Open Access article distributed under the terms of the Creative Commons Attribution License (http://creativecommons.org/licenses/by/2.0), which permits unrestricted use, distribution, and reproduction in any medium, provided the original work is properly cited. 
membrane proteins, including, for example, CD44 [18], transglutaminase [19], the integrin $\alpha \mathrm{V}$ chain [20] or syndecan 1 [21] thus modulating cell signalling and the cellular functions mediated by these molecules.

MT1-MMP has been implicated in a wide spectrum of physiological and pathological cellular functions [22,23]. MT1-MMP expression, well documented in many tumours, has been correlated with key in vitro and in vivo processes of tumour progression including angiogenesis [24], cell migration and invasion [25], cell growth [26] and metastatic spread [27,28]. Inhibition or silencing of the protease has been found to significantly reduce the invasive phenotype of tumour cells implicating a leading role for MT1-MMP in such processes $[25,29]$.

MT1-MMP is a type I transmembrane protein with a very short intracellular domain (ICD) of just 21 amino acids. The MT1-MMP ICD has been reported to be required for cell migration and invasion [30-33] as well as tumour growth [34]. The identification of proteins interacting with the MT1-MMP ICD, such as MTCBP-1 [35], and glCqR [36] have also helped in defining new localisations and cellular functions for this protease. The MT1-MMP ICD has also been implicated in the internalisation [31] and the recycling of the protease to the cell surface [37]. Consistent with this, MT1-MMP ICD has been reported to interact with the $\mu 2$ subunit of the AP-2 complex [31] as well as with caveolin-1 [38]

To date, crucial information on the cellular function of the intracellular domain of the protease has been obtained following exogenous expression of mutant MT1-MMP ICD constructs [31,32,39,38,37,40,41,33] or constructs with a partially or completely deleted ICD $[30,42,26,43,40,34]$. In order to assess the role of the MT1-MMP ICD without using exogenously truncated or mutated forms of the protease, we decided to make use of PA technology.

In this study, we identify and characterize a PA, named swiggle, which interacts with the 21 amino acid ICD of MT1-MMP. Expression of swiggle in human cells was found to stimulate MT1-MMP mediated cell migration. Detailed analysis of the phenotypic effect of swiggle revealed that the PA inhibits internalization of MT1MMP resulting in the accumulation of the protease at the cell surface. Our data indicate that swiggle interacts with the LLY ${ }^{573}$ motif in the MT1-MMP ICD and competes with the $\mu 2$ subunit of the AP- 2 complex in cells, thereby inhibiting the endocytosis of MT1-MMP.

\section{Results}

Isolation of peptide aptamers that interact with the MT1-MMP ICD

In order to identify PAs that interact with the MT1MMP ICD, a yeast two-hybrid screen was performed as previously described [1]. The 21 amino acid ICD of MT1-MMP was fused to the LexA DNA-binding domain (DBD) to generate the bait (LexA-MT1). As prey constructs, we used a library of $10^{6}$ unique $10-$ amino acid residue peptides that were inserted into the active loop of the E. coli thioredoxin (TrxA) scaffold protein. The prey constructs were transformed into the EGY42 yeast strain, which was then mated with EGY48 cells expressing LexA-MT1. Replica plating of the resulting diploids to selective media gave rise to 78 colonies where the $L E U 2$ reporter gene was activated. From these, only two plasmids were isolated that, when re-transformed into fresh EGY42 cells, still led to the activation of the $L E U 2$ and $L a c Z$ reporter genes in the presence of LexA-MT1. These two PAs were named swiggle and 76. Sequence analysis revealed that, as expected, swiggle comprises a 10 amino acid peptide within TrxA (Figure 1A). PA 76 was found to comprise a 25 amino acid sequence carboxy-terminal to the active loop of TrxA (Figure 1A). Peptides longer than 10 residues arise when two or more peptide-encoding oligonucleotides ligate to each other during library construction. In this case, the 3' of the fused oligonucleotide encodes an in-frame stop codon. In contrast to swiggle, PA 76 is not constrained (in 2 dimensions) at the carboxy-terminus and can be described as a linear peptide fused to the carboxy-terminus of a truncated TrxA fragment (Figure 1A), although it is possible that residues in this "peptide" form ionic or hydrophobic interactions with expressed regions of the TrxA scaffold, leading to at least some element of three-dimensional constraint. Blast searches of Genbank with each PA insert sequence revealed no similarity with known proteins.

To confirm the interaction of the selected PAs with MT1-MMP ICD, yeast interaction mating experiments were performed [44]. Haploid yeast strains expressing the LexA DNA-binding domain alone (LexA-DBD), LexA DBD fusions to the MT1-MMP ICD (LexA-MT1) or Cdk4 (LexA-Cdk4) were mated with strains expressing $\mathrm{B} 42$ activation domain (AD) fusions to TrxA (ADTrxA), swiggle (AD-swiggle), 76 (AD-76) or Cyclin D1 (AD-CyclinD1). We included in this assay a fusion of the AD to a mutant variant of swiggle, called s14, identified by random mutagenesis, which no longer binds to the LexA-MT1 fusion protein. s14 differs from swiggle by a single amino acid: GGLIPCYFMH in swiggle to GGLIPCYFTH in s14 (Figure 1A). Resulting diploids were grown on selective media to identify positive (Figure $1 \mathrm{~B}$, grey squares) or negative (Figure $1 \mathrm{~B}$, white squares) interactions. As expected, a clear interaction was observed between the LexA-Cdk4 and AD-CyclinD1 pair used as a positive control (Figure 1B). LexA-MT1 did not bind to AD-TrxA, AD-s14 or AD-CyclinD1 but 


\section{A \\ TrxA N-TrxA-TrxA-C \\ swiggle N-TrxA-GGLIPCYFMH-TrxA-C \\ s14 N-TrxA-GGLIPCYFTH-TrxA-C \\ 76 N-TrxA-GQVITWLLLEgpKVPTDSDRLVgpE* \\ B

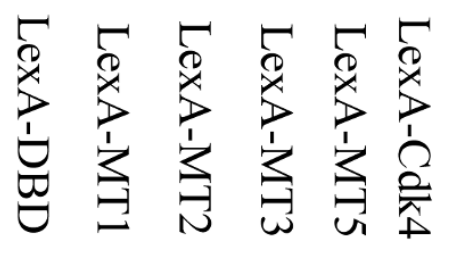

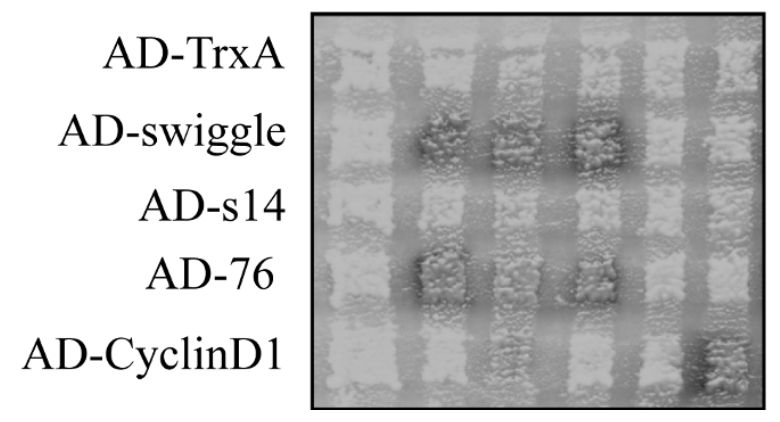

Figure 1 Isolation and validation of PAs interacting with MT1-MMP ICD. (A) Schematic representation of the TrXA scaffold and the PAs swiggle, 76, and s14. The sequences of the peptide inserted in TrxA (swiggle, s14) or fused to the N-terminal region of TrxA (76) are detailed. The point mutation in the sequence of s14 is depicted in bold and the amino acids in lower cases in PA 76 represent linkers between the multiple peptides. ${ }^{*}$ denotes the stop codon. (B) Swiggle interacts with the MT1-MMP ICD in a yeast-two hybrid interaction assay. EGY48 cells expressing LexA-DBD, LexA-MT1, LexA-MT2, LexA-MT3, LexA-MT5 or LexA-Cdk4 were mated with EGY42 cells expressing AD-TrXA, AD-swiggle, AD-s14, AD-76 or AD-CyclinD1 and plated onto selective media.

a clear interaction with AD-swiggle or AD-76 (Figure 1B) could be observed confirming that both PAs interact, via the inserted peptide, with the MT1-MMP ICD. In some experiments, a weak interaction between the LexA-DBD and AD-76 could also be observed, suggesting that PA 76 may also recognize sequences or surfaces from the LexA-DBD (data not shown). No interaction was detected between the LexA-DBD and AD-TrxA, AD-swiggle, AD-s14, AD-76 or AD-CyclinD1 (Figure $1 B)$. AD-swiggle was also found to interact with the ICD of MT2-MMP and MT3-MMP (LexA-MT2 and -MT3 in Figure 1B). AD-76 clearly interacted with LexA-MT3 and a weak interaction with LexA-MT2 was observed. $\mathrm{AD}$-swiggle and AD-76 did not interact with the ICD of MT5-MMP (LexA-MT5 in Figure 1B). Taken together, our data clearly demonstrate an interaction between the MT1-MMP ICD and both PAs. The weak interaction between AD-76 and LexA-DBD, coupled with the truncated structure of PA 76 and its instability when expressed in E. coli and mammalian cells (data not shown) led us to focus on swiggle in subsequent experiments. 


\section{GFP-swiggle co-immunoprecipitates with MT1-MMP in MCF7 cells}

These interactions between swiggle and the MT1-MMP ICD led us to test whether the two proteins could also interact when co-expressed in mammalian cells. TrxAbased PAs have previously been reported to be occasionally difficult to express in mammalian cells [45]. This was also the case for swiggle with poor expression observed in all the cell lines tested (data not shown). Increased swiggle stability and improved detection by western blot were achieved by fusing GFP to the amino terminus of the PA (Figure 2A). Addition of the tag also allowed detection of the PA by fluorescence microscopy. GFP was also added to the amino terminus of TrxA and s14 to generate GFP-TrxA and GFP-s14, respectively. We used the human MCF7 breast carcinoma cells, which do not naturally express MT1-MMP [46]. mRNA expression for MT2- and MT3-MMP in these cells is very low (our unpublished data and [26]). MCF7 cells were co-transfected with MT1-MMP, and either GFPswiggle or GFP-TrxA. Total cell lysates were subjected to immunoprecipitation with an anti-GFP antibody followed by Western blot analysis with an anti-MT1-MMP antibody (Figure 2B). No MT1-MMP was found associated with the immunoprecipitates when the anti-GFP antibody was omitted (Figure 2B, lanes 1 and 2, top panel) eliminating the possibility of non-specific binding of the GFP-tagged constructs or MT1-MMP to the beads. MT1-MMP was clearly found to co-immunoprecipitate with GFP-swiggle (Figure 2B, lane 4, top panel and Figure $2 \mathrm{C}$, lane 4, bottom panel), but not with GFPTrxA (Figure 2B, lane 3, top panel) or GFP-s14 (Figure $2 \mathrm{C}$, lane 3 , bottom panel). Together our data demonstrate that swiggle can recognise and interact with the MT1-MMP ICD within human cells.

\section{GFP-swiggle increases MT1-MMP-mediated cell migration}

The interaction between the intracellular domain of MT1-MMP and swiggle in human cells led us to ask whether we could detect functional effects of the PA on an ICD-mediated cellular function of the protease. The MT1-MMP ICD has previously been reported to play an important role in promoting cell migration [42,39]. In order to test whether swiggle could alter ICD-dependent MT1-MMP-mediated cell migration, we performed a cell migration assay $[18,31,47,33]$. Untransfected MCF7 cells as well as cells expressing MT1-MMP alone, MT1MMP and either GFP-s14 or GFP-swiggle were plated on colloidal gold-coated coverslips. After 24 hours incubation at $37^{\circ} \mathrm{C}$, the areas of the phagokinetic tracks generated by cell migration were measured. As expected, very little migration was observed for untransfected MCF7 cells (Figure 3A). Expression of MT1-MMP alone resulted in increased ( 3 fold in our case) cell migration compared to untransfected cells (Figure 3A) as previously observed $[39,42,48]$. To our surprise, expression of MT1-MMP and GFP-swiggle (Figures 3A and 3C) resulted in a considerable increase ( 5.5 fold) in cell migration compared to cells expressing MT1-MMP alone (Figure 3C). Expression of GFP-s14 did not have any effect on MT1-MMP-mediated cell migration (Figures 3A and 3C). All told, cells co-expressing MT1MMP and swiggle showed a 15 -fold enhancement in migration compared to untransfected MCF7 cells. Together, these observations indicate that expression of GFP-swiggle can affect a cellular function of the intracellular domain of MT1-MMP.

\section{GFP-swiggle increases expression of MT1-MMP at the cell surface}

Another observed role for the ICD is the internalisation of MT1-MMP from the plasma membrane $[31,32,49]$. The amplification of MT1-MMP-mediated cell migration observed after expression of GFP-swiggle could therefore be the result of an increased expression of the protease at the cell surface. To test this hypothesis, total exposed cell surface proteins of MCF7 cells over-expressing MT1-MMP, and either GFP, GFP-TrxA, GFP-s14 or GFP-swiggle were biotinylated and immunoprecipitated using an anti-biotin antibody. The presence of MT1-MMP was then detected in the complexes by immunoblotting. Inspection of total cell lysates indicated that the absolute levels of MT1-MMP were unaffected by co-expression of any of the GFP fusions. Of this cellular pool, a similar amount of MT1-MMP was detected at the cell surface of MCF7 cells co-expressing GFP (Figure 4, lane 1), GFP-TrxA (Figure 4, lane 2) or GFPs14 (Figure 4, lane 3). In contrast, the cell surface expression of the protease was clearly increased when GFP-swiggle was co-expressed with MT1-MMP (Figure 4, lane 4).

The activity of cell-surface localised MT1-MMP can be assessed using a Texas Red-labelled gelatin (TR-gelatin) degradation assay [50]. MCF7 cells transfected with expression constructs for either MT1-MMP, a catalytically inactive MT1-MMP E240A mutant or an ICDdeleted MT1-MMP (MT1-MMP $\triangle \mathrm{ICD}$ ) together with either GFP-swiggle or GFP-s14 were plated onto TRgelatin coated slides and incubated at $37^{\circ} \mathrm{C}$. As expected, untransfected MCF7 cells or cells expressing the catalytically inactive MT1-MMP E240A mutant were unable to degrade the TR-gelatin and this result was unaffected by co-expression of either GFP-s14 or GFP-swiggle (Figure 5C). Expression of active MT1-MMP alone in MCF7 cells resulted in a clear degradation of the TRgelatin (Figure $5 \mathrm{C}$ ) as previously observed in $\mathrm{CHO}-\mathrm{K} 1$ and CHO L761 cells expressing the protease [50,51]. A similar level of TR-gelatin degradation was also observed 


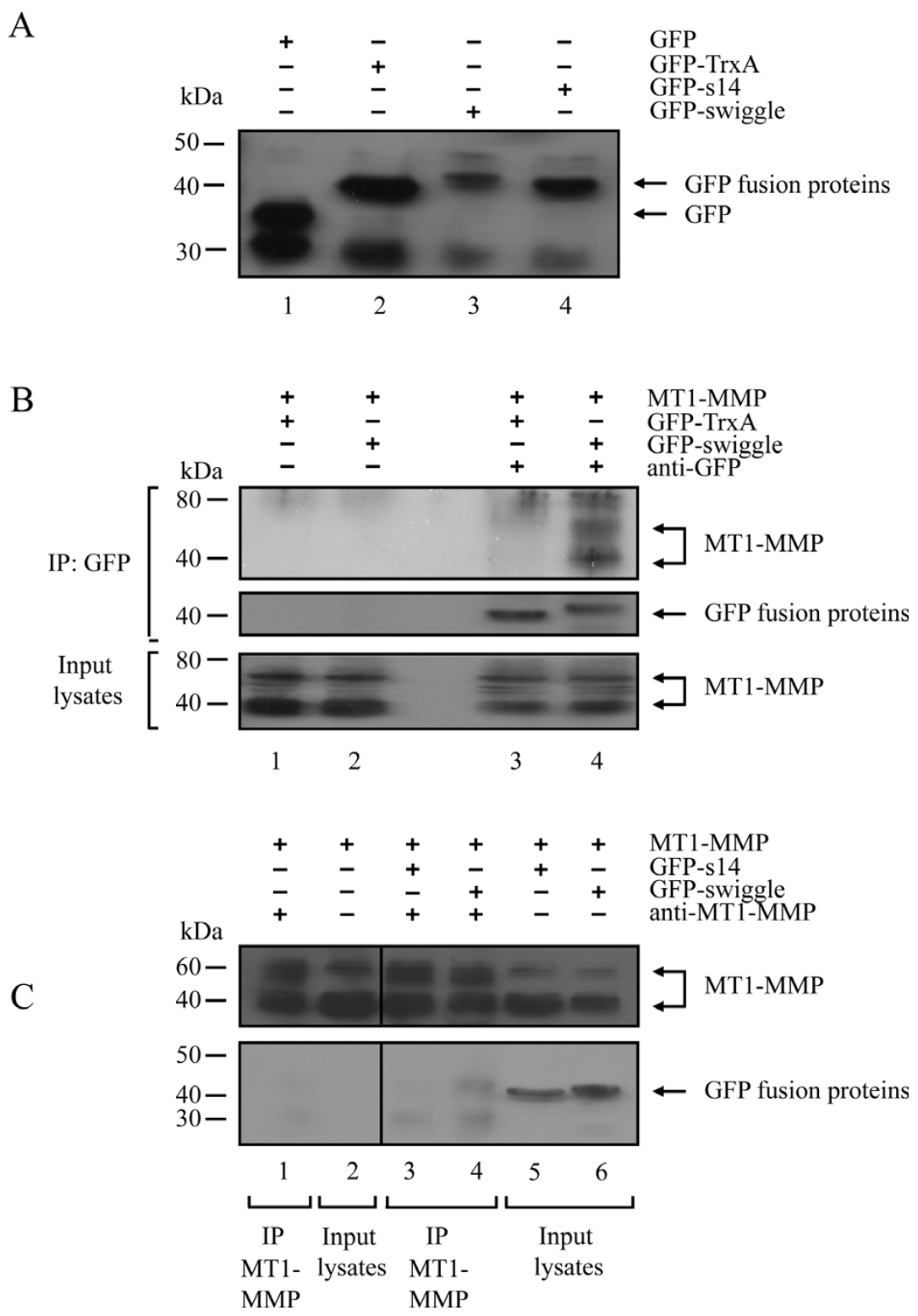

Figure 2 GFP-swiggle co-immunoprecipitates with MT1-MMP. (A) Western blot analysis of protein extracts prepared from MCF7 expressing GFP (lane 1), GFP-TrxA (lane 2), GFP-s14 (lane 3) or GFP-swiggle (lane 4) using an anti-GFP polyclonal serum. (B) Cell lysates prepared from MCF7 cells expressing MT1-MMP and GFP-TrxA (lanes 1 and 3), MT1-MMP and GFP-swiggle (lanes 2 and 4) were immunoprecipitated with an anti-GFP polyclonal antibody (lanes 3 and 4). The presence of MT1-MMP (top panel) and GFP-TRxA and GFP-swiggle (middle panel) in the immunocomplexes was monitored by Western blotting. The expression level of MT1-MMP in the input lysates was analysed by Western blot (bottom panel). (C) Cell lysates from MCF7 cells expressing MT1-MMP (lanes 1 and 2), MT1-MMP and GFP-s14 (lanes 3 and 5), MT1-MMP and GFP-swiggle (lanes 4 and 6) were immunoprecipitated with an anti-MT1-MMP pAb (lanes 1, 3 and 4). MT1-MMP, GFP-s14 or GFP-swiggle were detected in the input lysates (lanes 2, 5 and 6) and immunoprecipitated materials (lanes 1, 3 and 4) using an anti-MT1-MMP pAb or an anti-GFP polyclonal serum, respectively.

in cells co-expressing MT1-MMP and GFP-s14 (Figures $5 \mathrm{~A}$ and $5 \mathrm{C}$ ). In contrast, expression of MT1-MMP together with GFP-swiggle resulted in a 2.5 fold increase in the average area of TR-gelatin degradation per cell (Figures 5B and 5C) compared to MCF7 cells expressing MT1-MMP alone or together with GFP-s-14 (Figure $5 C)$. Increased TR-gelatin degradation was not observed in MCF7 cells expressing an active MT1-MMP with a deleted ICD (MT1-MMP $\triangle \mathrm{ICD}$ ) [52] or in cells co-expressing MT1-MMP $\triangle \mathrm{ICD}$ and GFP-swiggle or GFP-s14 (Figure 5C). Together, these data show that GFP-swiggle is able to increase the levels of MT1-MMP activity at the cell surface through interaction with the MT1-MMP ICD. Consistent with the increased level of 
A

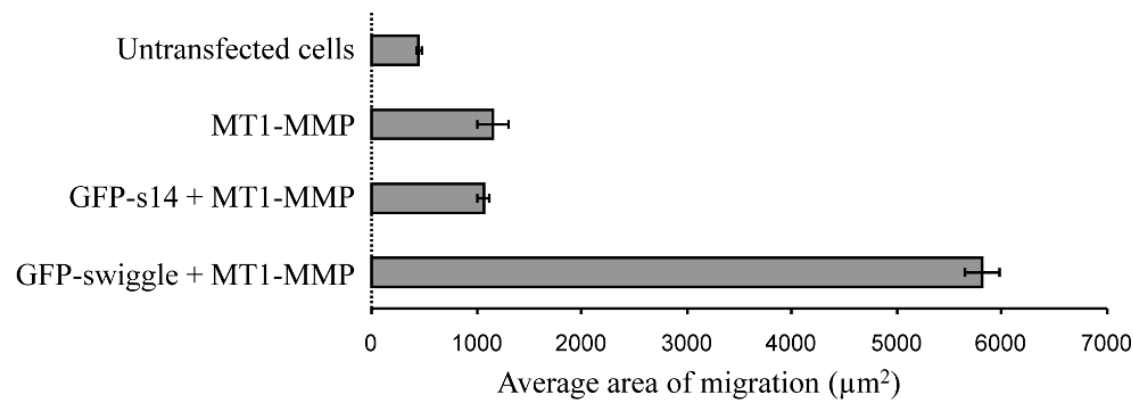

$\mathrm{B}$

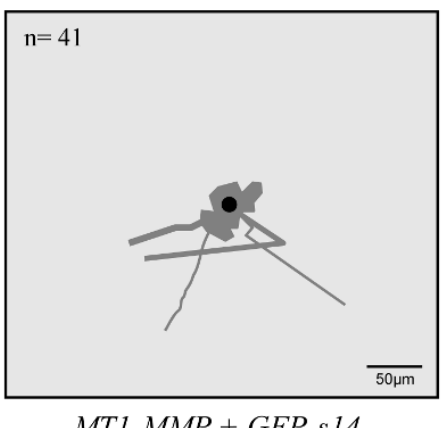

$M T 1-M M P+G F P-s 14$

$\mathrm{C}$

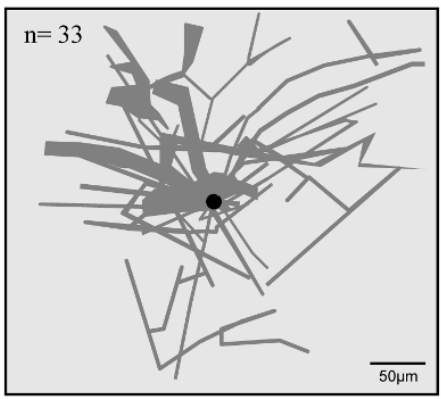

$M T 1-M M P+G F P$-swiggle

Figure 3 GFP-swiggle increases MT1-MMP mediated cell migration. (A) Untransfected MCF7 cells or cells expressing MT1-MMP alone or together with GFP-s14, or GFP-swiggle were incubated on colloidal gold-coated coverslips for 24 hours at $37^{\circ} \mathrm{C}$. Cells were then fixed and immunostained with an MT1-MMP antibody. The area of migration of at least 50 cells was measured and averaged. Representative phagokinetic tracks generated by MCF7 cells expressing MT1-MMP and (B) GFP-s14 or (C) GFP-swiggle.

MT1-MMP protein at the surface of cells expressing GFP-swiggle, these data also confirm that the increase of the protease at the cell surface is mediated by the interaction between GFP-swiggle and the ICD of MT1MMP.

\section{Swiggle inhibits MT1-MMP internalization}

The simplest explanation for the swiggle- and ICDmediated increased expression of MT1-MMP at the cell surface is that GFP-swiggle expression results in a perturbation of the internalization of the protease [49,31]. We tested whether expression of GFP-swiggle could interfere with the internalization of the protease by performing an antibody internalization assay using the N175 anti-MT1-MMP pAb. This antibody is directed against the whole extracellular domain of the protease and recognises full length as well as the $45 \mathrm{kDa}$ inactive form of the protease $[49,50]$. MCF7 cells expressing 


\begin{tabular}{l}
\hline IP: anti-biotin \\
Input Lysates
\end{tabular}

MT1-MMP, and either GFP-s14 (Figure 6, panels A to $\mathrm{H}$ ) or GFP-swiggle (Figure 6, panels I to P) were incubated with an anti-MT1-MMP antibody on ice, and then warmed to $37^{\circ} \mathrm{C}$ to restore endocytosis. In cells expressing MT1-MMP alone (data not shown) or MT1MMP and GFP-s14 (Figure 6, panels $A$ to $H$ ), the antibody-bound MT1-MMP originally present at the cell surface (time zero; Figure 6, panel A) was quickly internalized at $37^{\circ} \mathrm{C}$. Accumulation of vesicles containing antibody-bound MT1-MMP was clearly observed in the cytoplasm of the cells expressing GFP-s14 (Figure 6, panels B, C and D), demonstrating that the MT1-MMP antibody complex was internalized in these cells. In contrast, in MCF7 cells expressing MT1-MMP and GFPswiggle (Figure 6, panels I to P), we observed a marked reduction of vesicles containing antibody-bound MT1MMP, with most of the MT1-MMP antibody complex present at the cell surface when the cells were incubated at $37^{\circ} \mathrm{C}$ (Figure 6, panels J, K and L). A low level of internalization of antibody bound MT1-MMP complexes could however be detected by 50 minutes (Figure 6, panel L) in cells expressing GFP-swiggle. Quantification of MT1-MMP endocytosis MCF7 cells transfected with MT1-MMP and GFP-s14 or MT1-MMP and GFPswiggle after $0,10,30$ or 50 minutes at $37^{\circ} \mathrm{C}$ is presented in Figure 7.

\section{Swiggle interacts with the MT1-MMP LLY ${ }^{573}$ internalization motif}

The internalisation of MT1-MMP has been shown to be able to occur via clathrin- or caveolin-mediated pathways [49,53,31,32]. Because MCF7 cells do not express detectable levels of caveolin-1 [54-58], we asked whether GFP-swiggle was able to interfere with the clathrinmediated internalisation of the protease.
Clathrin-mediated endocytosis of MT1-MMP has previously been shown to involve the $\mu 2$ subunit of the adaptor protein AP-2, which interacts with the LLY ${ }^{573}$ motif found in the MT1-MMP ICD [31]. Therefore, the inhibition of MT1-MMP internalization observed following expression of GFP-swiggle could potentially result from a disruption of the interaction between MT1-MMP and $\mu 2$. The first test of this hypothesis was to ask whether the LLY ${ }^{573}$ motif required for $\mu 2$ binding is also required for binding by swiggle. We therefore generated a LexA-MT1 LLY/A triple mutant, where the LLY $^{573}$ motif in the MT1-MMP ICD was replaced by $\mathrm{AAA}^{573}$, and tested its interaction with $\mathrm{AD}$-swiggle in the yeast two-hybrid interaction assay. As before, we were able to detect a strong interaction in yeast expressing LexA-MT1 and AD-swiggle (Figure 8A; compare to Figure $1 \mathrm{~B})$. In contrast, no interaction was found between LexA-MT1 LLY/A and AD-swiggle (Figure 8A) suggesting that the LLY ${ }^{573}$ motif of MT1-MMP plays a crucial role in the interaction between swiggle and the MT1-MMP ICD.

If swiggle and $\mu 2$ both bind to the LLY ${ }^{573}$ motif of MT1-MMP, then expression of swiggle should competitively inhibit the interaction between $\mu 2$ and MT1-MMP in cells. To test this idea, MCF7 cells were transiently cotransfected with MT1-MMP alone or with MT1-MMP together with GFP-s14 or GFP-swiggle. Total cell lysates were subjected to immunoprecipitation with the antiMT1-MMP antibody and immune complexes were probed with anti- $\mu 2$, -MT1-MMP and -GFP antibodies. As shown in Figure 8B, we observed a clear co-immunoprecipitation of MT1-MMP and $\mu 2$ when the protease is expressed alone (Figure $8 \mathrm{~B}$, lane 2), or in the presence of GFP-s14 (Figure 8B, lane 3). In contrast, we were unable to detect $\mu 2$ in complexes immunoprecipitated from 


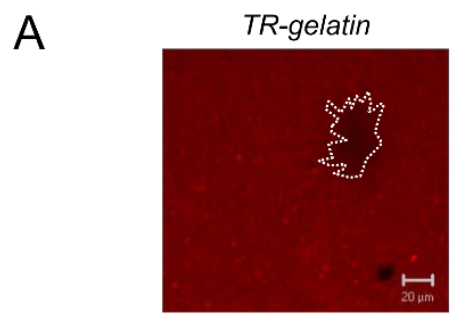

B

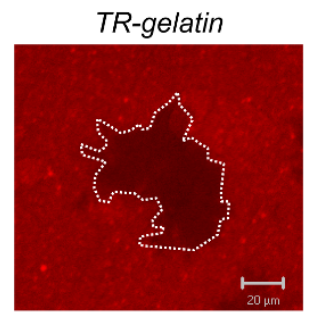

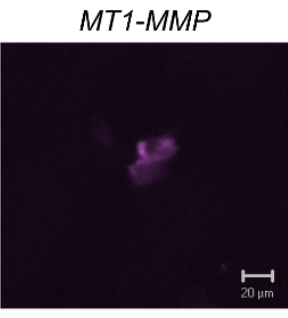

MT1-MMP

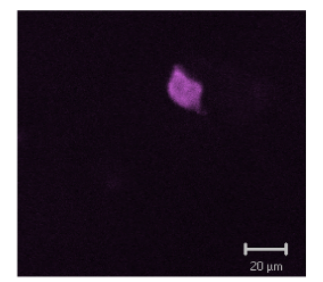

GFP-s14

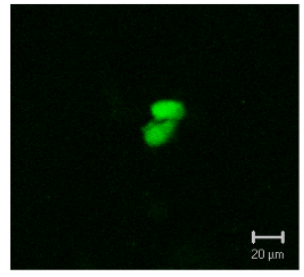

GFP-swiggle

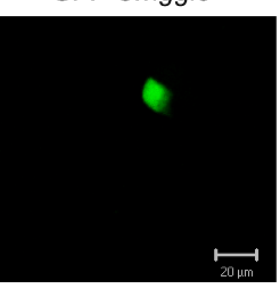

C

Untransfected

pCDNA3.1 + GFP-s14

pCDNA3.1 + GFP-swiggle

MT1-MMP

MT1-MMP + GFP-s14

MT1-MMP + GFP-swiggle

MT1-MMP E240A

MT1-MMP E240A + GFP-s14

MT1-MMP E240A + GFP-swiggle

MT1-MMP $\triangle \mathrm{ICD}$

MT1-MMP $\triangle I C D+$ GFP-s14

MT1-MMP $\triangle I C D+$ GFP-swiggle

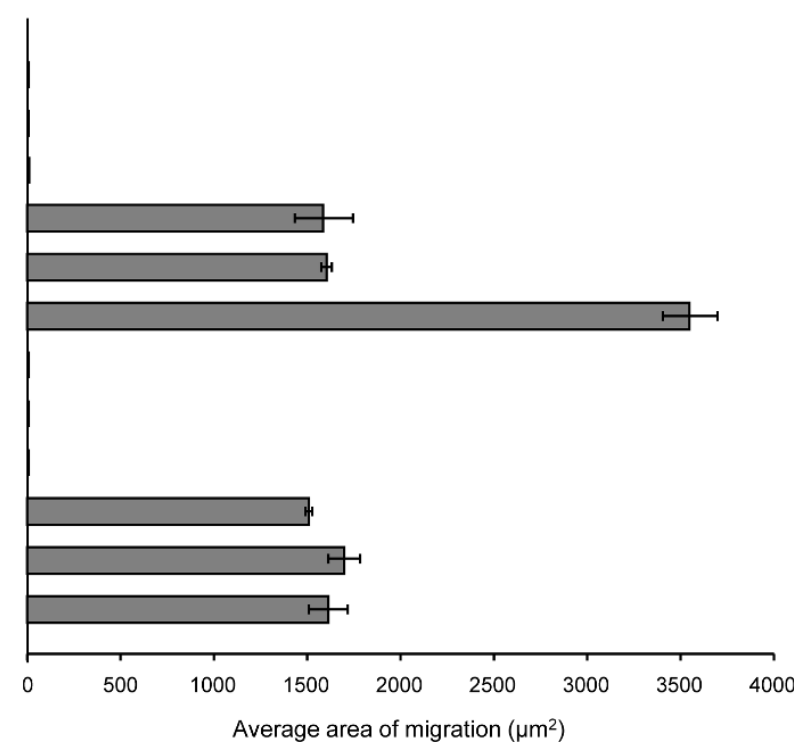

Figure 5 GFP-swiggle increases MT1-MMP-mediated Texas Red-gelatin degradation. Example of Texas-Red gelatin degradation (white dotted line) by MCF7 cells expressing MT1-MMP and (A) GFP-s14 or (B) GFP-swiggle after 16 hours incubation at $37^{\circ} \mathrm{C}$. GFP-s14 or GFP-swiggle (green) and MT1-MMP (purple) expression were detected by immunofluorescence. Bar $=20 \mu \mathrm{m}$ (C) Quantification of the area of migration of at least 50 untransfected MCF7 cells or 50 cells transfected with GFP-s14, GFP-swiggle, MT1-MMP, MT1-MMP + GFP-s14, MT1-MMP + GFP-swiggle,

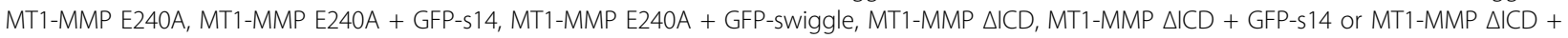
GFP-swiggle. Data represent average area of migration \pm s.e.m..

MCF7 cells expressing MT1-MMP and GFP-swiggle (Figure 8B, lane 4), thus demonstrating that expression of the PA inhibits the formation of a complex between the protease and the $\mu 2$ subunit. Taken together, our data suggest that the inhibition of MT1-MMP endocytosis observed following expression of swiggle probably results from the interaction of the PA with the LLY ${ }^{573}$ motif of the MT1-MMP ICD, thus disrupting the interaction of the MT1-MMP ICD with the $\mu 2$ subunit. Our results thus suggest a potential mechanism for the amplification of the effects of MT1-MMP on cell migration by GFPswiggle. They also demonstrate that swiggle binding to 


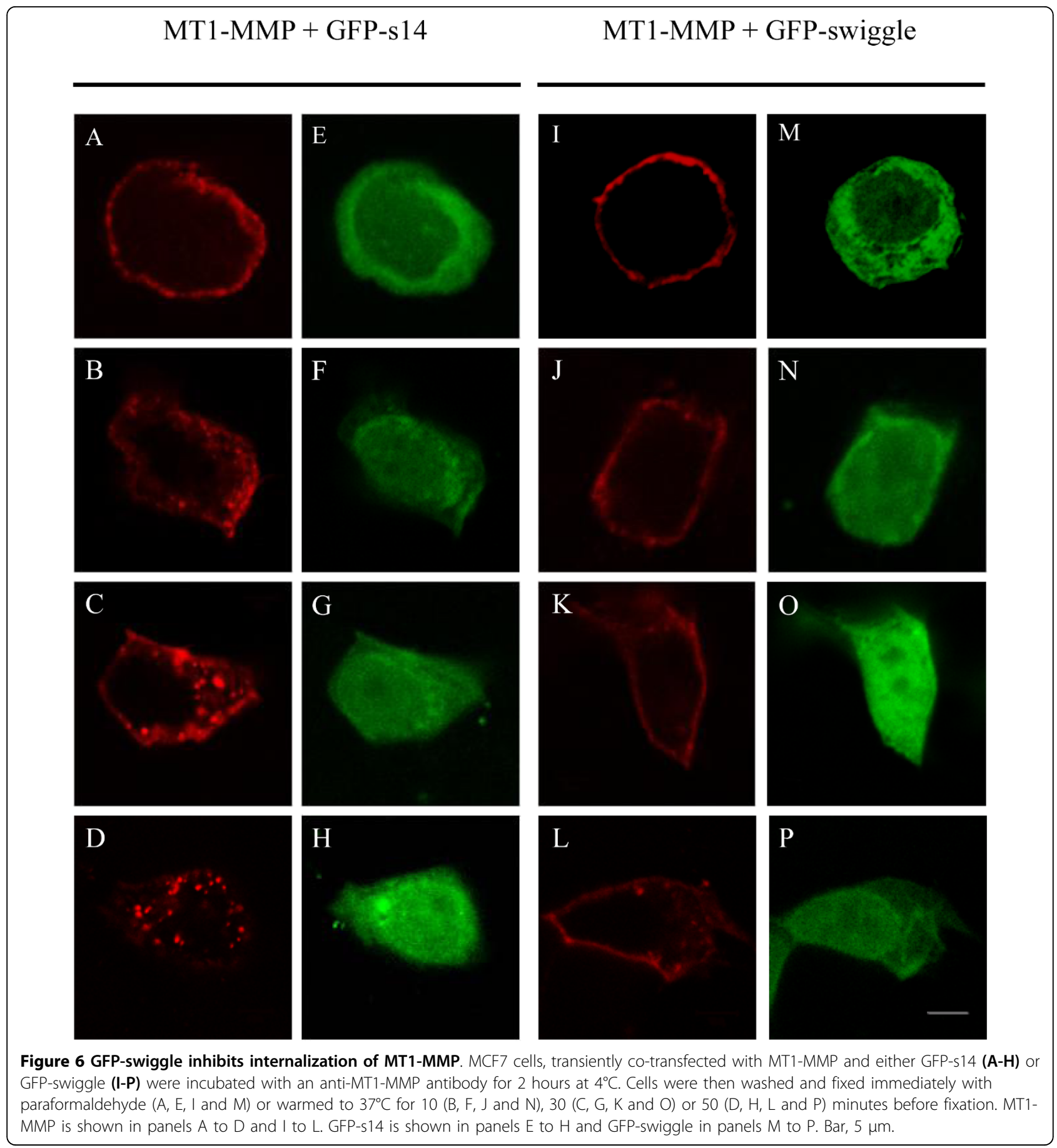

the ICD can inhibit endocytosis of MT1-MMP without affecting communication between the ICD and the machinery required for cell migration.

\section{Discussion}

In this study, we have described the isolation and characterisation of a PA, called swiggle, which binds to the ICD of the membrane-bound matrix metalloproteinase,
MT1-MMP. Our results have several implications for PA technology. Firstly, we have demonstrated that PAs can be successfully obtained against small intracellular domains of transmembrane proteins. Although short peptides have previously been used in yeast two hybrid interaction assays, for example to map interaction domains, the 21 amino acid MT1-MMP ICD bait is approximately three times smaller than the previous 


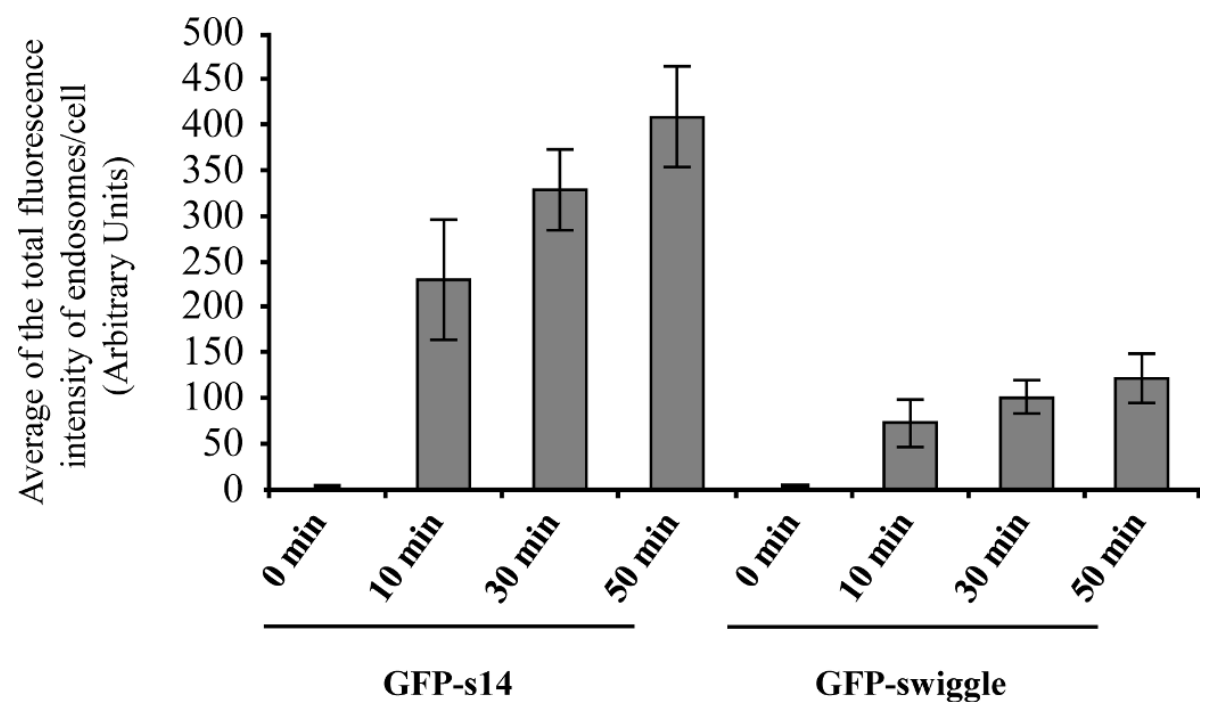

Figure 7 Quantification of MT1-MMP endocytosis in MCF7 cells transfected with MT1-MMP and GFP-s14 or GFP-swiggle. MCF7 cells transiently co-transfected with MT1-MMP and either GFP-s14 or GFP-swiggle were incubated with an anti-MT1-MMP antibody for 2 hours at $4^{\circ} \mathrm{C}$. Cells were fixed immediately ( $0 \mathrm{~min}$ ) or after 10,30 or 50 minutes at $37^{\circ} \mathrm{C}$. Data represent the average of the total fluorescence intensity of endosomes per cell \pm s.e.m..

smallest published bait used in a screen, a 59 amino acid C-terminal portion of the HPV-16 E7 protein [6]. Our bait is also more than six times smaller than the only other published ICD used in a PA screen, the 133 amino acid ICD of the EGF receptor [7]. Given the dearth of tools to directly study the biology of the MT1MMP ICD, which could be attributed to its small size, this study raises the possibility that PA technology could be used to generate tools to study the biology of other small intracellular domains, such as integrins, that were previously difficult to study.

PAs have traditionally been found to produce inhibitory phenotypes by blocking certain functions of their target proteins $[10,3,11,5,8,13,9]$. For example, PAs that interacted with the human papilloma virus (HPV) E6 oncoprotein could block E6-mediated degradation of p53, resulting in increased $\mathrm{p} 53$ protein levels, growth inhibition and apoptosis in HPV-positive HPV16 cells [5]. In contrast, we found that expression of GFP-swiggle resulted in an increase in both MT1-MMP-mediated TR-gelatin degradation and cell migration. Furthermore, GFP-swiggle appeared to affect the amount of MT1-MMP at the cell surface. This increased gain of function migratory phenotype caused by GFP-swiggle is unique, although it is consistent with the original prediction for the mechanism of PA function [1] in that it appears to result from a loss of function, namely reduction of the rate of endocytosis of MT1-MMP. Although a previous study has described a PA that stimulates its target protein, calcineurin, this PA was identified from an anti-proliferative phenotypic screen, rather than a yeast-two hybrid screen with a defined bait [59]. The phenotype of this PA is also the opposite of swiggle, with a gain of function of its target resulting in a loss of function phenotype. Together, these studies thus demonstrate the broad applicability of PA technology to the dissection of cell biology.

The increase in MT1-MMP mediated cell migration and TR-gelatin degradation mediated by GFP-swiggle most probably results from the inhibition of endocytosis leading to increased levels of the protease at the cell surface. However, ICD mutants used in other studies that resulted in increased levels of MT1-MMP protein at the cell surface did not cause any effect on cell migration/invasion [30,31,33]. For example, over-expression of wild type MT1-MMP leads to increased cell migration and invasion, but truncations of the ICD including the $L_{L Y}{ }^{573}$ residues, or removal of the whole of the ICD prevented these effects $[30,31,33]$. This appears paradoxical as truncations that decrease the rate of MT1-MMP internalization should result in more MT1-MMP being present at the cell surface, and hence more proteolytic/ migratory activity. One possible explanation for this observation is that the LLY ${ }^{573}$ motif of the MT1-MMP ICD is required both for clathrin-mediated internalisation and MT1-MMP-mediated cell migration. However, no tools previously existed to test this idea. Our results now show that the expression of GFP-swiggle reduces the rate of internalization of MT1-MMP and results in an increased amount of MT1-MMP at the cell surface, mimicking this aspect of LLY ${ }^{573}$ mutation. But unlike the ICD LLY ${ }^{573}$ mutation, GFP-swiggle also allows cell migration to proceed. 


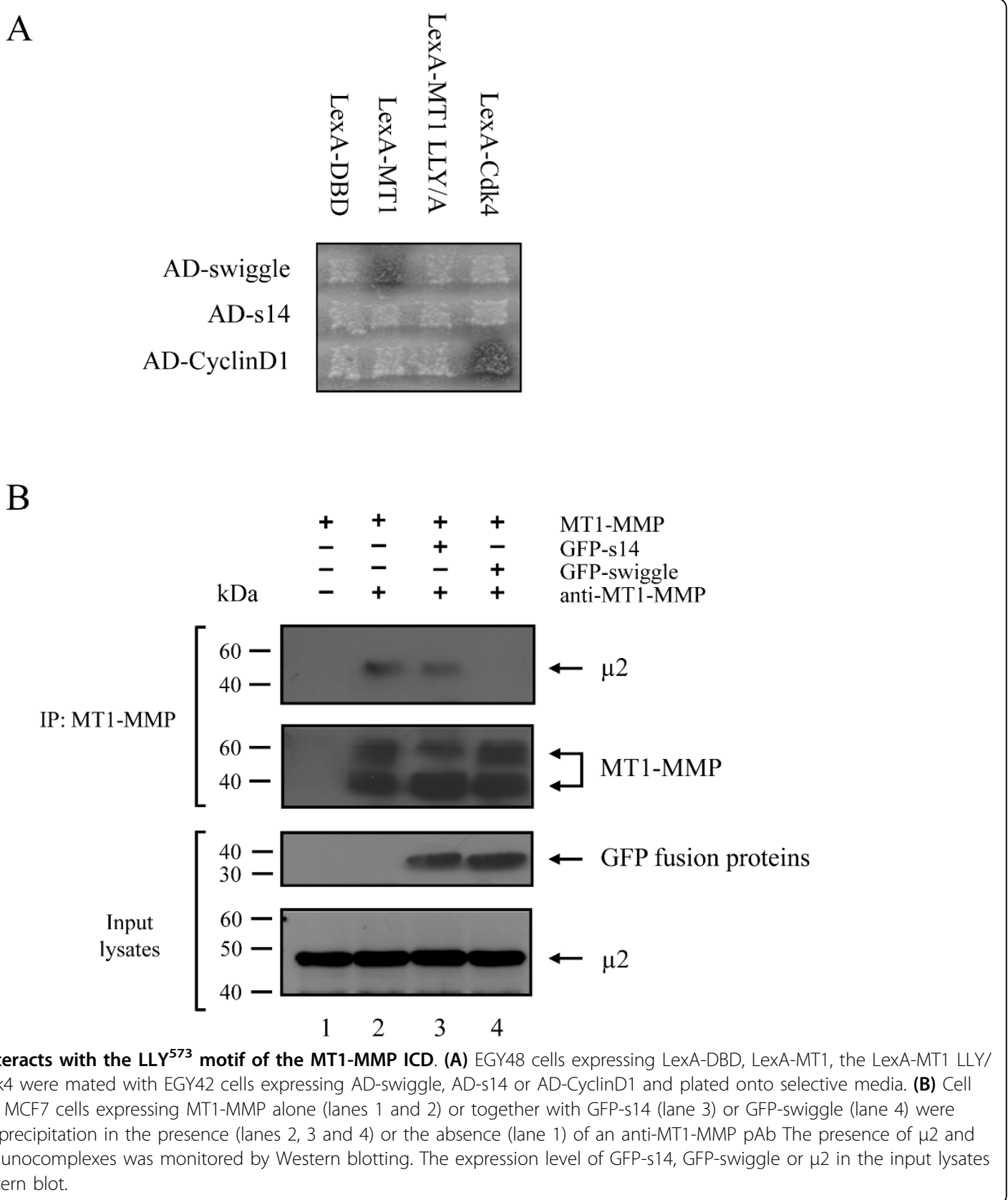

A potential caveat of our experiments as well as those of $[30,31,33]$, is that the majority of the assays that were used were only sensitive to over-expressed levels of MT1MMP. While this may reflect the pathological situation in cancer cells, further work is needed to assess whether GFP-swiggle can perturb other functions of MT1-MMP in normal cells through the development of assays that are sensitive to endogenous levels of MT1-MMP.

\section{Conclusions}

In summary, we have identified and characterized a PA that, when expressed in mammalian cells, can inhibit the clathrin-mediated internalisation of MT1-MMP by interacting with the normal function of the ICD of the protease. In addition to laying the ground-work for the study of the mechanism of endocytic recycling of transmembrane MMPs, this PA should be a useful tool in further studies of MT1-MMP in the existing wide range of biological and disease models.

\section{Methods}

All chemicals were AnalaR grade and were purchased from Sigma Aldrich Chemical Co. (Poole, UK) unless indicated otherwise. 


\section{DNA constructions}

Oligonucleotides coding for a PGGG linker followed by MT1-MMP, MT2-MMP, MT3-MMP, or MT5-MMP intracellular domain (ICD) were annealed and cloned downstream of the LexA DNA binding domain (DBD) in pEG202 (Origene, Rockville, USA) to generate LexAMT1, -MT2, -MT3 and-MT5. The MT1-MMP ICD LLY/A mutant in pEG202 was created by site-directed mutagenesis (Stratagene, La Jolla, CA, USA). Swiggle, and s14, all in pJG4-5 (Origene), were amplified by PCR and subcloned into pIRES2eGFP (BD Clontech, UK). Swiggle and s14 were excised from the above constructs and subcloned into BretGFP-C1 (PerkinElmer, Boston, MA, USA). TrxA, excised from pJM-1 (gift from R. Brent, Berkeley, USA) was subcloned into BretGFP-C2. $\mathrm{N}$-terminally $\mathrm{His}_{6}$-tagged swiggle was generated by cloning swiggle into pET32a (Merck Biosciences Ltd., Nottingham, UK).

\section{Yeast two-hybrid screen}

The peptide aptamer (PA) library containing a B42 AD fusion to $1 \times 10^{6}$ different PAs was constructed as described in [45] and transformed into the reporter $S$. cerevisiae strain EGY48 (MAT $\alpha$ leu2::LexA 6op-LEU2 his3 trp1 ura3) [60]. These cells were mated with EGY42 cells (MATa leu2 his3 trp1 ura3) [10]) carrying LexA-MT1. The two-hybrid mating screen was performed essentially as described by [60]. Interactors, selected on Ura ${ }^{-} \mathrm{His}^{-}{ }^{-} \mathrm{Trp}^{-} \mathrm{Leu}^{-} / \mathrm{X}$-Gal, Gal, Raff plates after four days at $30^{\circ} \mathrm{C}$, were picked and the plasmids rescued into $E$. coli $\mathrm{KC} 8$ cells. The plasmids were transformed back into EGY48 to confirm interaction with LexA-MT1 in EGY42 using an interaction-mating matrix. LexA-Cdk4 and AR cDNAs were kindly provided by P. Hinds and M. Lu (Harvard Medical School, USA). AD-CyclinD1 cDNA was from R. Brent (Molecular Sciences Institute, Berkeley CA, USA).

\section{Isolation of mutants of swiggle by PCR mutagenesis of the swiggle peptide insert}

PCR mutagenesis of the swiggle peptide insert was performed as previously described [61] except for the following alterations. Mutated swiggle sequences were ligated into RsrII-cut pJM-1 vector and were transformed into XL-10 gold E. coli cells (Invitrogen Ltd., Paisley, UK). Plasmid DNA was isolated using Qiagen midi-prep DNA extraction kit (Qiagen, Crawley, UK), and transformed (1 $\mu \mathrm{g})$ into EGY48 containing LexA-MT1 and pJK103 [61]. Positive (blue) and negative (white) interactors were selected on Ura ${ }^{-} \mathrm{His}^{-}{ }^{-} \mathrm{Trp}^{-} \mathrm{Leu}^{-} / \mathrm{X}-\mathrm{Gal}$, Gal, Raff plates for four days, picked and the plasmids rescued into E. coli KC8 cells. Plasmids were transformed back into EGY48 to confirm interaction with LexA-MT1 in EGY42 using an interaction-mating matrix.

\section{Cell culture and transfections}

All cell culture reagents were purchased from Invitrogen Ltd. unless indicated. MCF7 cells, purchased from ECACC (Salisbury, UK), were maintained in DMEM, supplemented with $10 \%(\mathrm{vol} / \mathrm{vol})$ fetal calf serum (FCS, Hyclone Laboratories, UT, USA) and $2 \mathrm{mM}$ L-glutamine at $37^{\circ} \mathrm{C}$ in $5 \% \mathrm{CO} 2$ atmosphere. Transfections were performed using FuGENE-6 reagent (Roche Diagnostics, Lewes, UK) according to manufacturer's instructions.

\section{Immunoprecipitation and western blotting}

MCF7 cells were transfected for 48 hours with either $0.4 \mu \mathrm{g}$ GFP-swiggle and $0.6 \mu \mathrm{g}$ MT1-MMP constructs, or $0.4 \mu \mathrm{g}$ GFP-TrxA and 0.6 $\mu \mathrm{g}$ MT1-MMP in 6-well plates. After 2 washes with ice-cold PBS, cells were lysed for 15 minutes on ice under rocking conditions in $200 \mu \mathrm{l}$ of lysis buffer $(50 \mathrm{mM}$ Tris- $\mathrm{HCl}, \mathrm{pH} 7.4$, $100 \mathrm{mM} \mathrm{NaCl}, 2 \mathrm{mM}$ EDTA, 1\% Triton X-100, $60 \mathrm{mM}$ octyl-D-glucoside) supplemented with complete protease inhibitor cocktail (Roche Molecular Biochemical, Hertfordshire, UK), sonicated ( 80 Volts for 10 seconds, Sonics and Material Inc., Suffolk, UK) and centrifugated $\left(10\right.$ minutes at $15000 \mathrm{~g}$ at $\left.4^{\circ} \mathrm{C}\right)$. An aliquot $(10 \%)$ of the protein extract was kept and analysed by Western blot (input lysate). The remaining protein extract was incubated for 2 hours at $4^{\circ} \mathrm{C}$ with an anti-GFP rabbit polyclonal serum (dilution 1/2200). Protein G sepharose beads ( $20 \mu \mathrm{l}$ of slurry) were then added and the mixture rotated for a further 2 hours at $4^{\circ} \mathrm{C}$. Beads were washed four times with $1 \times$ PBS, once with PBS diluted 5 times in distilled water and finally were resuspended in Laemmli sample buffer (LSB). Immunoprecipitates and input lysates were boiled for 5 minutes, resolved on $12 \%$ SDS-polyacrylamide gels, and electrotransferred onto PVDF membrane (Millipore, Watford, UK). Western blots were carried out as previously described [45]. Rabbit anti-GFP serum (Abcam, Cambridge, UK) was used at a 1:2000 dilution. The anti-MT1-MMP sheep N175 $\mathrm{pAb}$, directed against the entire extracellular of the protease [49,50], was used at $10 \mu \mathrm{g} / \mathrm{ml}$.

\section{Cell surface biotinylation of proteins}

Cell surface biotinylation was carried out as previously described [49], except for the following alterations. MCF7 cells $\left(1 \times 10^{5}\right)$ were transfected with $0.4 \mu \mathrm{g}$ GFPswiggle and $0.6 \mu \mathrm{g}$ MT1-MMP, $0.4 \mu \mathrm{g}$ GFP-TrxA and $0.6 \mu \mathrm{g}$ MT1-MMP, $0.4 \mu \mathrm{g}$ GFP-s14 and $0.6 \mu \mathrm{g}$ MT1MMP, or 0.4 $\mu \mathrm{g}$ GFP and 0.6 $\mu \mathrm{g}$ MT1-MMP in 6-well plates. PBS buffer was substituted for Soerensen buffer (SBS). Cells were incubated for 30 minutes in ice-cold PBS containing $0.5 \mathrm{mg} / \mathrm{ml}$ of NHS-SS-Biotin (Pierce Biochemical, Rockford, USA) and lyzed for 15 minutes at $4^{\circ} \mathrm{C}$ in $200 \mu \mathrm{l}$ ice-cold RIPA buffer containing protease inhibitor III cocktail (Calbiochem Biochemical, 
West Drayton, UK). The lysate was cleared by centrifugation $\left(16000 \mathrm{~g}\right.$ for 5 minutes at $\left.4{ }^{\circ} \mathrm{C}\right)$ and incubation with protein A/G plus-agarose beads $(25 \mu \mathrm{l}$; Santa Cruz Biotechnology, Santa Cruz, USA) for 1 hour at $4^{\circ} \mathrm{C}$. An aliquot of the whole cell lysate $(20 \mu \mathrm{l}$; input lysate) was kept for western blot analysis. Anti-biotin mAb (12 $\mu \mathrm{g}$; Jackson Immunoresearch Ltd., Soham, UK) and Protein A/G Plus agarose beads $(30 \mu \mathrm{l})$ were then added to the extract and incubated for 1 hour at $4^{\circ} \mathrm{C}$ under constant rotation. Beads were washed five times with ice-cold RIPA buffer, resuspended in LSB and processed for western blotting as previously described.

\section{Immunofluorescence microscopy}

Cells seeded on glass coverslips were washed in PBS, fixed at room temperature (RT) in $4 \%(\mathrm{wt} / \mathrm{vol}$ ) paraformaldehyde (PFA, BDH, Poole, UK) for 5 minutes and washed twice with PBS. For permeabilized cells, coverslips were incubated in $0.2 \%$ Triton-X100 in PBS for 5 minutes at RT, and washed three times in $2 \times \mathrm{PBS}$. Cells were blocked for 30 minutes at RT with PBS containing $10 \%$ FCS and $10 \mu \mathrm{g} / \mathrm{ml} \mathrm{BSA}$, and then incubated with the anti-MT1-MMP sheep pAb $(10 \mu \mathrm{g} / \mathrm{ml})$ for 16 hours at $4^{\circ} \mathrm{C}$ in PBS containing $10 \mu \mathrm{g} / \mathrm{ml}$ BSA. After 3 washes in PBS, cells were incubated for 1 hour at RT with fluorescently-conjugated secondary antibody (Jackson Immunoresearch Ltd.) in PBS and according to the manufacturer's instructions. Coverslips were washed repeatedly in PBS, and mounted onto glass slides using Vectashield containing diamidino-2-phenylindole (DAPI, Vector Laboratories, Burlingame, USA). Images of fluorescently labelled cells were collected using a Zeiss LSM510 Metaconfocal microscope in a single focal plane (Carl Zeiss Ltd., Welwyn Garden City, UK).

\section{Texas Red-labelled Gelatin Degradation Assay}

Texas Red labelled-gelatin was coated, as previously described by [50] on the glass surface of 8 well Labtek culture slides (Becton Dickinson Labware, USA) and incubated for 2 hours at $37^{\circ} \mathrm{C}$ in DMEM containing $10 \%$ FCS. Untransfected MCF7 cells $\left(5 \times 10^{4}\right.$ per well) were then seeded on the fluorescent gelatin and incubated for 16 hours at $37^{\circ} \mathrm{C}$. Cell transfections were carried out using FuGENE-6 $(0.75 \mu \mathrm{l})$ and $250 \mathrm{ng}$ of DNA (ratio used). Cells were then washed in warmed PBS, fixed with $4 \%(\mathrm{w} / \mathrm{v})$ PFA in PBS and then processed immunofluorescence microscopy using the anti-MT1-MMP sheep pAb as described above. A Cy5 conjugated donkey anti-sheep secondary antibody (1:200 dilution) was used (Jackson Immunoresearch).

For each condition, pictures of at least 50 cells in a single focal plane were taken with a Zeiss 510 Meta confocal microscope. The area of TR-gelatin degradation was then measured with Zeiss AIM software (version 3.2).

\section{Phagokinetic track colloidal gold cell migration assay}

The phagokinetic track colloidal gold cell migration assay was performed as described previously [18]. Colloidal gold-coated coverslips were placed in a 12-well plate, and transfected MCF7 cells were seeded at $2 \times$ $10^{3}$ cells per well. After 24 hours incubation at $37^{\circ} \mathrm{C}$, cells were fixed as previously described and phagokinetic tracks were visualized using bright field illumination with a Zeiss 510 Meta confocal microscope. The area of migration for at least 50 transfected cells was measured with Zeiss AIM software and averaged.

\section{MT1-MMP antibody internalization assay}

MCF7 cells, co-transfected with GFP-swiggle $(0.4 \mu \mathrm{g})$ and MT1-MMP $(0.6 \mu \mathrm{g})$, or GFP-s14 $(0.4 \mu \mathrm{g})$ and MT1MMP $(0.6 \mu \mathrm{g})$, were seeded on glass coverslips in 6 -well plates. After 48 hours transfection, cells were washed twice with ice-cold PBS and incubated with the affinity purified N175 anti-MT1-MMP sheep pAb $(5 \mu \mathrm{g} / \mathrm{ml})$ at $4^{\circ} \mathrm{C}$ for 2 hours. Coverslips were then washed twice with ice-cold PBS to remove unbound antibody and fixed immediately (zero minute timepoint) in 4\% PFA for 10 minutes or placed at $37^{\circ} \mathrm{C}$ for 10,30 and 50 minutes in prewarmed media before fixation. Cells were permeabilized and processed for immuno-fluorescence microscopy as previously described. Endocytosis was quantified by measuring the fluorescence intensity of all endocytic vesicles per cell using Metamorph imaging software version 6.1 (Molecular Devices Ltd., Wokingham, UK) as previously described by [62]. At least 5 cells were used for time 0 and 15 cells for the other time points.

\section{Abbreviations}

PA: peptide aptamer; ECM: Extra-cellular matrix; MT1-MMP: membrane-type I matrix metalloproteinase; ICD: intracellular domain; DBD: DNA-binding domain; AD: activation domain.

\section{Acknowledgements}

We would like to thank Gillian Murphy, Ron Laskey, Sharon Tate, Vihandha Wickramasinghe and Anasuya Chattopadhyay for their advice and support. We thank Yoshifumi Itoh (Kennedy Institute of Rheumatology) for his help and advice with the colloidal gold assay. We also thank Neil Taylor, William English and Sue Atkinson for critical reading of this manuscript. We would like to acknowledge the support of the Gates Cambridge Trust (RDW), the Medical Research Council (RDW and PKF), Cancer Research UK and Hutchison Whampoa Limited (CR) and the University of Cambridge.

\section{Author details}

'MRC Cancer Cell Unit, Hutchison/MRC Research Centre, Hills Road, University of Cambridge, Cambridge, CB2 OXZ, UK. ${ }^{2}$ University of Cambridge, Department of Oncology, Cambridge Research Centre, Li Ka Shing Centre, Robinson Way, Cambridge, CB2 ORE, UK. ${ }^{3}$ Leeds Institute of Molecular Medicine, St James' University Hospital, University of Leeds, Leeds LS7 9TF, UK.

\section{Authors' contributions}

RDW carried out the molecular genetic studies, participated in the sequence alignment and drafted the manuscript. PKF conceived the study, participated in its design and coordination and helped to draft the manuscript. CR 
participated in the design and coordination of the study and helped to draft the manuscript. All authors read and approved the final manuscript.

Received: 27 October 2009 Accepted: 23 July 2010

Published: 23 July 2010

\section{References}

1. Colas P, Cohen B, Jessen T, Grishina I, McCoy J, Brent R: Genetic selection of peptide aptamers that recognize and inhibit cyclin-dependent kinase 2. Nature 1996, 380:548-550.

2. Binz HK, Amstutz P, Pluckthun A: Engineering novel binding proteins from nonimmunoglobulin domains. Nat Biotechnol 2005, 23:1257-1268.

3. Kolonin MG, Finley RL Jr: Targeting cyclin-dependent kinases in Drosophila with peptide aptamers. Proc Natl Acad Sci USA 1998, 95:14266-14271.

4. Blum JH, Dove SL, Hochschild A, Mekalanos JJ: Isolation of peptide aptamers that inhibit intracellular processes. Proc Natl Acad Sci USA 2000, 97:2241-2246.

5. Butz K, Denk C, Ullmann A, Scheffner M, Hoppe-Seyler F: Induction of apoptosis in human papillomaviruspositive cancer cells by peptide aptamers targeting the viral E6 oncoprotein. Proc Natl Acad Sci USA 2000, 97:6693-6697.

6. Nauenburg S, Zwerschke W, Jansen-Durr P: Induction of apoptosis in cervical carcinoma cells by peptide aptamers that bind to the HPV-16 E7 oncoprotein. FASEB J 2001, 15:592-594.

7. Buerger C, Nagel-Wolfrum K, Kunz C, Wittig I, Butz K, Hoppe-Seyler F, Groner B: Sequence-specific peptide aptamers, interacting with the intracellular domain of the epidermal growth factor receptor, interfere with Stat3 activation and inhibit the growth of tumor cells. $J$ Biol Chem 2003, 278:37610-37621.

8. Nagel-Wolfrum K, Buerger C, Wittig I, Butz K, Hoppe-Seyler F, Groner B: The interaction of specific peptide aptamers with the DNA binding domain and the dimerization domain of the transcription factor Stat3 inhibits transactivation and induces apoptosis in tumor cells. Mol Cancer Res 2004, 2:170-182.

9. Chattopadhyay A, Tate SA, Beswick RW, Wagner SD, Ko Ferrigno P: A peptide aptamer to antagonize BCL-6 function. Oncogene 2006, 25:2223-2233

10. Cohen BA, Colas $P$, Brent $R$ : An artificial cell-cycle inhibitor isolated from a combinatorial library. Proc Natl Acad Sci USA 1998, 95:14272-14277.

11. Fabbrizio E, Le Cam L, Polanowska J, Kaczorek M, Lamb N, Brent R, Sardet C: Inhibition of mammalian cell proliferation by genetically selected peptide aptamers that functionally antagonize E2F activity. Oncogene 1999, 18:4357-4363.

12. Bottger A, Bottger V, Sparks A, Liu WL, Howard SF, Lane DP: Design of a synthetic Mdm2-binding mini protein that activates the p53 response in vivo. Curr Biol 1997, 7:860-869.

13. Nouvion AL, Thibaut J, Lohez OD, Venet $\mathrm{S}$, Colas $\mathrm{P}$, Gillet $\mathrm{G}$, Lalle P: Modulation of $\mathrm{Nr}-13$ antideath activity by peptide aptamers. Oncogene 2007, 26(5):701-10.

14. Barbolina MV, Stack MS: Membrane type 1-matrix metalloproteinase: substrate diversity in pericellular proteolysis. Semin Cell Dev Biol 2008, 19:24-33.

15. Zucker S, Pei D, Cao J, Lopez-Otin C: Membrane type-matrix metalloproteinases (MT-MMP). Curr Top Dev Biol 2003, 54:1-74

16. Will H, Atkinson SJ, Butler GS, Smith B, Murphy G: The soluble catalytic domain of membrane type 1 matrix metalloproteinase cleaves the propeptide of progelatinase $A$ and initiates autoproteolytic activation. Regulation by TIMP-2 and TIMP-3. J Biol Chem 1996, 271:17119-17123.

17. Knauper V, Will H, Lopez-Otin C, Smith B, Atkinson SJ, Stanton H, Hembry RM, Murphy G: Cellular mechanisms for human procollagenase-3 (MMP-13) activation. Evidence that MT1-MMP (MMP-14) and gelatinase a (MMP-2) are able to generate active enzyme. J Biol Chem 1996, 271:17124-17131.

18. Kajita M, Itoh $\mathrm{Y}$, Chiba T, Mori H, Okada A, Kinoh H, Seiki M: Membranetype 1 matrix metalloproteinase cleaves CD44 and promotes cell migration. J Cell Biol 2001, 153:893-904.

19. Belkin AM, Zemskov EA, Hang J, Akimov SS, Sikora S, Strongin AY: Cellsurface-associated tissue transglutaminase is a target of MMP-2 proteolysis. Biochemistry (Mosc) 2004, 43:11760-11769.
20. Ratnikov BI, Rozanov DV, Postnova TI, Baciu PG, Zhang H, DiScipio RG, Chestukhina GG, Smith JW, Deryugina El, Strongin AY: An alternative processing of integrin alpha(v) subunit in tumor cells by membrane type-1 matrix metalloproteinase. J Biol Chem 2002, 277:7377-7385.

21. Endo K, Takino T, Miyamori H, Kinsen H, Yoshizaki T, Furukawa M, Sato H: Cleavage of syndecan-1 by membrane type matrix metalloproteinase-1 stimulates cell migration. J Biol Chem 2003, 278:40764-40770.

22. Holmbeck K, Bianco P, Yamada S, Birkedal-Hansen H: MT1-MMP: a tethered collagenase. J Cell Physiol 2004, 200:11-19.

23. Itoh Y, Seiki M: MT1-MMP: a potent modifier of pericellular microenvironment. J Cell Physiol 2006, 206:1-8.

24. Genis L, Galvez BG, Gonzalo P, Arroyo AG: MT1-MMP: universal or particular player in angiogenesis? Cancer Metastasis Rev 2006, 25:77-86.

25. Sabeh F, Ota I, Holmbeck K, Birkedal-Hansen H, Soloway P, Balbin M, LopezOtin C, Shapiro S, Inada M, Krane S, et al: Tumor cell traffic through the extracellular matrix is controlled by the membrane-anchored collagenase MT1-MMP. J Cell Biol 2004, 167:769-781.

26. Hotary KB, Allen ED, Brooks PC, Datta NS, Long MW, Weiss SJ: Membrane type I matrix metalloproteinase usurps tumor growth control imposed by the three-dimensional extracellular matrix. Cell 2003, 114:33-45.

27. Seiki M: Membrane-type 1 matrix metalloproteinase: a key enzyme for tumor invasion. Cancer Lett 2003, 194:1-11.

28. Vihinen $\mathrm{P}$, Kahari VM: Matrix metalloproteinases in cancer: prognostic markers and therapeutic targets. Int J Cancer 2002, 99:157-166.

29. Ueda J, Kajita M, Suenaga N, Fujii K, Seiki M: Sequence-specific silencing of MT1-MMP expression suppresses tumor cell migration and invasion: importance of MT1-MMP as a therapeutic target for invasive tumors. Oncogene 2003, 22:8716-8722.

30. Lehti K, Valtanen H, Wickstrom SA, Lohi J, Keski-Oja J: Regulation of membrane-type-1 matrix metalloproteinase activity by its cytoplasmic domain. J Biol Chem 2000, 275:15006-15013.

31. Uekita T, Itoh Y, Yana I, Ohno H, Seiki M: Cytoplasmic tail-dependent internalization of membrane-type 1 matrix metalloproteinase is important for its invasion-promoting activity. I Cell Biol 2001, 155:1345-1356.

32. Jiang A, Lehti K, Wang X, Weiss SJ, Keski-Oja J, Pei D: Regulation of membrane-type matrix metalloproteinase 1 activity by dynaminmediated endocytosis. Proc Natl Acad Sci USA 2001, 98:13693-13698.

33. Anilkumar N, Uekita T, Couchman JR, Nagase H, Seiki M, Itoh Y: Palmitoylation at Cys574 is essential for MT1-MMP to promote cell migration. FASEB J 2005, 19:1326-1328.

34. D'Alessio S, Ferrari G, Cinnante K, Scheerer W, Galloway AC, Roses DF, Rozanov DV, Remacle AG, Oh ES, Shiryaev SA, et al: Tissue inhibitor of metalloproteinases-2 binding to membrane-type 1 matrix metalloproteinase induces MAPK activation and cell growth by a nonproteolytic mechanism. J Biol Chem 2008, 283:87-99.

35. Uekita T, Gotoh I, Kinoshita T, Itoh Y, Sato H, Shiomi T, Okada Y, Seiki M: Membrane-type 1 matrix metalloproteinase cytoplasmic tail-binding protein-1 is a new member of the Cupin superfamily. A possible multifunctional protein acting as an invasion suppressor down-regulated in tumors. J Biol Chem 2004, 279:12734-12743.

36. Rozanov DV, Ghebrehiwet B, Ratnikov B, Monosov EZ, Deryugina El, Strongin AY: The cytoplasmic tail peptide sequence of membrane type-1 matrix metalloproteinase (MT1-MMP) directly binds to $\mathrm{gClqR}$, a compartment-specific chaperone-like regulatory protein. FEBS Lett 2002, 527:51-57.

37. Wang X, Ma D, Keski-Oja J, Pei D: Co-recycling of MT1-MMP and MT3MMP through the trans-Golgi network. Identification of DKV582 as a recycling signal. J Biol Chem 2004, 279:9331-9336.

38. Labrecque L, Nyalendo C, Langlois S, Durocher Y, Roghi C, Murphy G, Gingras D, Beliveau R: Src-mediated tyrosine phosphorylation of caveolin1 induces its association with membrane type 1 matrix metalloproteinase. J Biol Chem 2004, 279:52132-52140.

39. Rozanov DV, Deryugina El, Ratnikov BI, Monosov EZ, Marchenko GN, Quigley JP, Strongin AY: Mutation analysis of membrane type-1 matrix metalloproteinase (MT1-MMP). The role of the cytoplasmic tail Cys(574), the active site Glu(240), and furin cleavage motifs in oligomerization, processing, and self-proteolysis of MT1-MMP expressed in breast carcinoma cells. J Biol Chem 2001, 276:25705-25714.

40. Sounni NE, Roghi C, Chabottaux V, Janssen M, Munaut C, Maquoi E, Galvez BG, Gilles C, Frankenne F, Murphy G, et al: Up-regulation of vascular 
endothelial growth factor-A by active membrane-type 1 matrix metalloproteinase through activation of Src-tyrosine kinases. J Biol Chem 2004, 279:13564-13574.

41. Nyalendo C, Michaud M, Beaulieu E, Roghi C, Murphy G, Gingras D, Beliveau R: Src-dependent Phosphorylation of Membrane Type I Matrix Metalloproteinase on Cytoplasmic Tyrosine 573: Role in endothelial and tumour cell migration. J Biol Chem 2007, 282:15690-15699.

42. Gingras D, Bousquet-Gagnon N, Langlois S, Lachambre MP, Annabi B, Beliveau R: Activation of the extracellular signal-regulated protein kinase (ERK) cascade by membrane-type-1 matrix metalloproteinase (MT1MMP). FEBS Lett 2001, 507:231-236

43. Rozanov DV, Deryugina El, Monosov EZ, Marchenko ND, Strongin AY: Aberrant, persistent inclusion into lipid rafts limits the tumorigenic function of membrane type- 1 matrix metalloproteinase in malignant cells. Exp Cell Res 2004, 293:81-95.

44. Finley RL Jr, Brent R: Interaction mating reveals binary and ternary connections between Drosophila cell cycle regulators. Proc Natl Acad Sci USA 1994, 91:12980-12984.

45. Woodman R, Yeh JT, Laurenson S, Ferrigno PK: Design and validation of a neutral protein scaffold for the presentation of peptide aptamers. $J \mathrm{Mol}$ Biol 2005, 352:1118-1133.

46. Deryugina El, Bourdon MA, Jungwirth K, Smith JW, Strongin AY: Functional activation of integrin alpha $\mathrm{V}$ beta 3 in tumor cells expressing membrane-type 1 matrix metalloproteinase. Int J Cancer 2000, 86:15-23.

47. Mori H, Tomari T, Koshikawa N, Kajita M, Itoh Y, Sato H, Tojo H, Yana Seiki M: CD44 directs membrane-type 1 matrix metalloproteinase to lamellipodia by associating with its hemopexin-like domain. EMBO J 2002, 21:3949-3959.

48. Sounni NE, Devy L, Hajitou A, Frankenne F, Munaut C, Gilles C, Deroanne C, Thompson EW, Foidart JM, Noel A: MT1-MMP expression promotes tumor growth and angiogenesis through an up-regulation of vascular endothelial growth factor expression. FASEB J 2002, 16:555-564.

49. Remacle A, Murphy G, Roghi C: Membrane type I-matrix metalloproteinase (MT1-MMP) is internalised by two different pathways and is recycled to the cell surface. J Cell Sci 2003, 116:3905-3916.

50. d'Ortho MP, Stanton H, Butler M, Atkinson SJ, Murphy G, Hembry RM: MT1MMP on the cell surface causes focal degradation of gelatin films. FEBS Lett 1998, 421:159-164.

51. Yana I, Weiss SJ: Regulation of membrane type-1 matrix metalloproteinase activation by proprotein convertases. Mol Biol Cell 2000, 11:2387-2401.

52. Cao J, Kozarekar P, Pavlaki M, Chiarelli C, Bahou WF, Zucker S: Distinct roles for the catalytic and hemopexin domains of membrane type 1-matrix metalloproteinase in substrate degradation and cell migration. J Biol Chem 2004, 279:14129-14139.

53. Galvez BG, Matias-Roman S, Yanez-Mo M, Vicente-Manzanares M, SanchezMadrid F, Arroyo AG: Caveolae are a novel pathway for membrane-type 1 matrix metalloproteinase traffic in human endothelial cells. Mol Biol Cell 2004, 15:678-687.

54. Lavie Y, Fiucci G, Liscovitch M: Up-regulation of caveolae and caveolar constituents in multidrug-resistant cancer cells. J Biol Chem 1998, 273:32380-32383.

55. Lee SW, Reimer CL, Oh P, Campbell DB, Schnitzer JE: Tumor cell growth inhibition by caveolin re-expression in human breast cancer cells. Oncogene 1998, 16:1391-1397.

56. Engelman JA, Zhang XL, Lisanti MP: Sequence and detailed organization of the human caveolin-1 and -2 genes located near the D7\$522 locus (7q31.1). Methylation of a CpG island in the $5^{\prime}$ promoter region of the caveolin-1 gene in human breast cancer cell lines. FEBS Lett 1999, 448:221-230.

57. Hurlstone AF, Reid G, Reeves JR, Fraser J, Strathdee G, Rahilly M, Parkinson EK, Black DM: Analysis of the CAVEOLIN-1 gene at human chromosome 7q31.1 in primary tumours and tumour-derived cell lines. Oncogene 1999, 18:1881-1890.

58. Fiucci G, Ravid D, Reich R, Liscovitch M: Caveolin-1 inhibits anchorageindependent growth, anoikis and invasiveness in MCF-7 human breast cancer cells. Oncogene 2002, 21:2365-2375.

59. de Chassey B, Mikaelian I, Mathieu AL, Bickle M, Olivier D, Negre D, Cosset FL, Rudkin BB, Colas P: An antiproliferative genetic screening identifies a peptide aptamer that targets calcineurin and up-regulates its activity. Mol Cell Proteomics 2007, 6:451-459.
60. Gyuris J, Golemis E, Chertkov H, Brent R: Cdi1, a human G1 and S phase protein phosphatase that associates with Cdk2. Cell 1993, 75:791-803.

61. Colas P, Cohen B, Ko Ferrigno P, Silver PA, Brent R: Targeted modification and transportation of cellular proteins. Proc Natl Acad Sci USA 2000, 97:13720-13725.

62. Raucher D, Sheetz MP: Membrane expansion increases endocytosis rate during mitosis. J Cell Biol 1999, 144:497-506.

doi:10.1186/1471-2121-11-58

Cite this article as: Wickramasinghe et al:: Peptide aptamers as new tools to modulate clathrin-mediated internalisation - inhibition of MT1-MMP internalisation. BMC Cell Biology 2010 11:58

\section{Submit your next manuscript to BioMed Central and take full advantage of:}

- Convenient online submission

- Thorough peer review

- No space constraints or color figure charges

- Immediate publication on acceptance

- Inclusion in PubMed, CAS, Scopus and Google Scholar

- Research which is freely available for redistribution 